\title{
EGTA reduces the inflorescence stem mechanical strength of herbaceous peony by modifying secondary wall biosynthesis
}

\author{
Yuhan Tang ${ }^{1}$, Daqiu Zhao ${ }^{1}$, Jiasong Meng ${ }^{1}$ and Jun Tao ${ }^{1}$
}

\begin{abstract}
The mechanical strength of inflorescence stems is an important trait in cut flowers. Calcium ions $\left(\mathrm{Ca}^{2+}\right)$ play a pivotal role in maintaining stem strength, but little is known about the underlying molecular mechanisms. In this study, we treated herbaceous peony (Paeonia lactiflora Pall.) with ethyl glycol tetraacetic acid (EGTA), an effective $\mathrm{Ca}^{2+}$ chelator, and used morphology indicators, spectroscopic analysis, histochemical staining, electron microscopy, and proteomic techniques to investigate the role of $\mathrm{Ca}^{2+}$ in inflorescence stem mechanical strength. The EGTA treatment reduced the mechanical strength of inflorescence stems, triggered the loss of $\mathrm{Ca}^{2+}$ from cell walls, and reduced lignin in thickened secondary walls in xylem cells as determined by spectroscopic analysis and histochemical staining. Electron microscopy showed that the EGTA treatment also resulted in significantly fewer xylem cell layers with thickened secondary walls as well as in reducing the thickness of these secondary walls. The proteomic analysis showed 1065 differentially expressed proteins (DEPS) at the full-flowering stage (S4). By overlapping the Kyoto encyclopedia of genes and genomes (KEGG) and gene ontology (GO) analysis results, we identified 43 DEPs involved in signal transduction, transport, energy metabolism, carbohydrate metabolism, and secondary metabolite biosynthesis. Using quantitative real-time polymerase chain reaction (qRT-PCR) analysis, we showed that EGTA treatment inhibited $\mathrm{Ca}^{2+}$ sensors and secondary wall biosynthesis-related genes. Our findings revealed that EGTA treatment reduced the inflorescence stem mechanical strength by reducing lignin deposition in xylem cells through altering the expression of genes involved in $\mathrm{Ca}^{2+}$ binding and secondary wall biosynthesis.
\end{abstract}

\section{Introduction}

Calcium ions $\left(\mathrm{Ca}^{2+}\right)$ play a key role in regulating plant growth and development, including cell wall formation ${ }^{1}$, osmotic regulation $^{2}$, cell division ${ }^{3}$, and resistance to biotic and abiotic stresses ${ }^{4-6}$. In plants, $\mathrm{Ca}^{2+}$ signals transient increases in cytosolic free $\mathrm{Ca}^{2+}$. Stimulus-induced increases in the concentration of free $\mathrm{Ca}^{2+}$ in the cytosol often occur as repetitive oscillations or spiking of cytosolic-free $\mathrm{Ca}^{2+} \cdot \mathrm{Ca}^{2+}$ encodes stimulus-specific information within a so-called $\mathrm{Ca}^{2+}$ signature, and thus

\footnotetext{
Correspondence: Jun Tao (taojun@yzu.edu.cn)

'Jiangsu Key Laboratory of Crop Genetics and Physiology, College of

Horticulture and Plant Protection, Yangzhou University, Yangzhou 225009

Jiangsu, China

These authors contributed equally: Yuhan Tang, Daqiu Zhao
}

defines the nature and magnitude of the response ${ }^{7}$. Recently, $\mathrm{Ca}^{2+}$ has received increasing attention due to its positive correlation with the straightness of herbaceous peony (P. lactiflora Pall.) inflorescence stems, which is a very important quality-assessment parameter for cut flowers ${ }^{8}$. Inflorescence stem straightness is mainly determined by its mechanical strength ${ }^{9}$. After analyzing the $\mathrm{Ca}^{2+}$ concentration of inflorescence stems in 76 different P. lactiflora cultivars, Li et al. ${ }^{10}$ found a significant positive correlation between $\mathrm{Ca}^{2+}$ content and mechanical strength in inflorescence stems. Spraying stems with exogenous $4 \%$ calcium chloride $\left(\mathrm{CaCl}_{2}\right)$ also enhanced inflorescence stem mechanical strength ${ }^{8,11}$. However, although the exogenous $\mathrm{Ca}^{2+}$ treatment enhances inflorescence stem mechanical strength, no studies have

\section{() The Author(s) 2019}

(c) (i) Open Access This article is licensed under a Creative Commons Attribution 4.0 International License, which permits use, sharing, adaptation, distribution and reproduction cc) in any medium or format, as long as you give appropriate credit to the original author(s) and the source, provide a link to the Creative Commons license, and indicate if changes were made. The images or other third party material in this article are included in the article's Creative Commons license, unless indicated otherwise in a credit line to the material. If material is not included in the article's Creative Commons license and your intended use is not permitted by statutory regulation or exceeds the permitted use, you will need to obtain permission directly from the copyright holder. To view a copy of this license, visit http://creativecommons.org/licenses/by/4.0/. 
reported the effects of $\mathrm{Ca}^{2+}$ deprivation on $P$. lactiflora inflorescence stem mechanical strength.

The mechanical strength in P. lactiflora inflorescence stem is related to wall thickness ${ }^{12}$. In plants, wall thickening happens after cell growth is arrested as protoplasts continue to secrete cellulose and other substances into the inner wall. Thickened cell walls are called secondary walls, and they are distributed around the vascular tissues and under the epidermal layer in stems, providing a major mechanical strength to plants ${ }^{13,14}$. Deposition of lignin in xylem elements and sclerenchyma cell walls is important for mechanical strength ${ }^{9}$. Perik et al. ${ }^{9}$ reported that in cut gerbera (Gerbera jamesonii cv. Tamara) flowers, inflorescence stem bending was associated with the absence of lignin deposition in sclerenchyma cells. This has also been verified in rice (Oryza sativa L.) brittle culm 3 mutants ${ }^{15}$. In addition to lignin, cellulose synthesis is also essential for proper secondary wall construction ${ }^{16}$.

$\mathrm{Ca}^{2+}$ plays a positive role in pollen tube cell wall formation in apple (Malus pumila Mill.) ${ }^{17}$ and in the fruit cell walls of jujube (Zizyphus jujuba Mill. cv. Dongzao) ${ }^{18}$. However, studies on the effects of $\mathrm{Ca}^{2+}$ on cell wall formation and mechanical strength have focused on the physiological level, and the underlying molecular mechanisms remain unclear. Here, we investigated the hypothesis that a lack of $\mathrm{Ca}^{2+}$ causes inflorescence stem bending due to reduced mechanical strength. Ethyl glycol tetraacetic acid (EGTA), a $\mathrm{Ca}^{2+}$ chelator that binds $\mathrm{Ca}^{2+19,20}$, was used for $\mathrm{Ca}^{2+}$ deprivation treatment. The relationship with mechanical strength was explored by studying the morphological indices of inflorescence stems and flowers, the extension of inflorescence stem secondary walls, inflorescence stem cell wall composition, protein changes in the inflorescence stem, and expression changes of secondary wall biosynthesis-related genes in the inflorescence stem.

\section{Results}

Morphological indices and photosynthetic characteristics

EGTA treatment significantly affected $P$. lactiflora growth and development. Specifically, the upper part of the P. lactiflora inflorescence stems was less straight after EGTA treatment compared to the control at all four flower-development stages (flower-bud stage (S1), pigmented stage (S2), unfold-petal stage (S3), and fullflowering stage (S4); Fig. 1a). To further investigate $P$. lactiflora morphological changes induced by EGTA treatment, five morphological indices, including the upper inflorescence stem mechanical strength, diameter and weight, and the flower diameter and weight at these four flower developmental stages were measured. Values for all five morphological indices were significantly lower in plants treated with EGTA compared to controls. The upper inflorescence stem mechanical strength, which was an average of $28 \%$ lower than the control, was consistent with the results observed by the naked eye (Fig. 1b). Additionally, values for these five morphological indices increased from S1 to S4 in both control and EGTAtreated plants. The effects of EGTA treatment on photosynthetic characteristics were also investigated, and the photosynthesis rate $(\mathrm{Pn})$ was significantly lower with EGTA treatment at S3 and S4 compared to the control (Fig. 1b). However, stomatal conductance (Gs) and transpiration rate $(\mathrm{Tr})$ showed no significant differences between the control and the EGTA treatment. Additionally, the values for Pn and Tr increased from S1 to S3 and then decreased from S3 to S4 in the control and EGTA-treated plants, whereas Gs remained the same from S1 to S2, decreased from S2 to S3, and increased from S3 to S4.

\section{Cell wall-composition analysis}

To address whether EGTA treatment altered the cell wall composition, $X$-ray photoelectron spectroscopy (XPS) and Fourier-transform infrared spectroscopy (FTIR) were performed. Peaks for carbon ${ }_{1 \mathrm{~s}}\left(\mathrm{C}_{1 \mathrm{~s}}\right)$, nitro$\operatorname{gen}_{1 \mathrm{~s}}\left(\mathrm{~N}_{1 \mathrm{~s}}\right)$, oxygen os $_{1 \mathrm{~s}}\left(\mathrm{O}_{1 \mathrm{~s}}\right)$, and calcium $2 \mathrm{p}\left(\mathrm{Ca}_{2 \mathrm{p}}\right)$ were identified in both control and EGTA-treated cell walls (Supplementary Table S1). The relative proportion of $\mathrm{N}$ within the cell wall decreased as the developmental stage progressed, whereas the relative proportions of $\mathrm{C}$ and $\mathrm{O}$ within the cell wall remained constant. The relative proportion of $\mathrm{Ca}$ within the cell wall increased during development. With EGTA treatment, no significant difference was observed in the relative proportion of these cell wall elements, but the relative proportions of $\mathrm{N}$ and Ca within the cell wall were significantly lower in EGTAtreated plants compared to the controls.

The characteristic spectra of the most cell wall chemical groups lie between 1800 and $800 \mathrm{~cm}^{-1}$. Functional groups were assigned to the spectral peaks as follows: 1740 (carbonyl $\mathrm{C}=\mathrm{O}$ ), 1640 (amide I $\mathrm{C}=\mathrm{O}$ ), 1510 (aromatic skeletal vibrations), 1465, 1425, 1325 (lignin), $1375(\mathrm{CH}$ band), 1245 (amide III in protein), and 1160, 1107, 1060 and $899 \mathrm{~cm}^{-1}(\mathrm{CHO})^{21,22}$. Although the FTIR spectra of cell walls in control and EGTA-treated plants were essentially similar, the relative absorbances of the peaks were different with EGTA treatment compared to the control (Fig. 2a). For example, the relative absorbances at $1325,1425,1465,1510$, and $1640 \mathrm{~cm}^{-1}$, which correspond to lignin or lignin-like structures, were lower in EGTAtreated plants, as were the relative absorbances at 899 , $1060,1107,1160,1245$, and $1375 \mathrm{~cm}^{-1}$, which correspond to polysaccharide-like cellulose structures.

Histochemical staining was used to verify the deposition of lignin on the secondary wall. Specifically, inflorescence stem transverse sections were stained with phloroglucinol-hydrochloric acid, which selectively stains lignified cell walls red, and were observed by light 


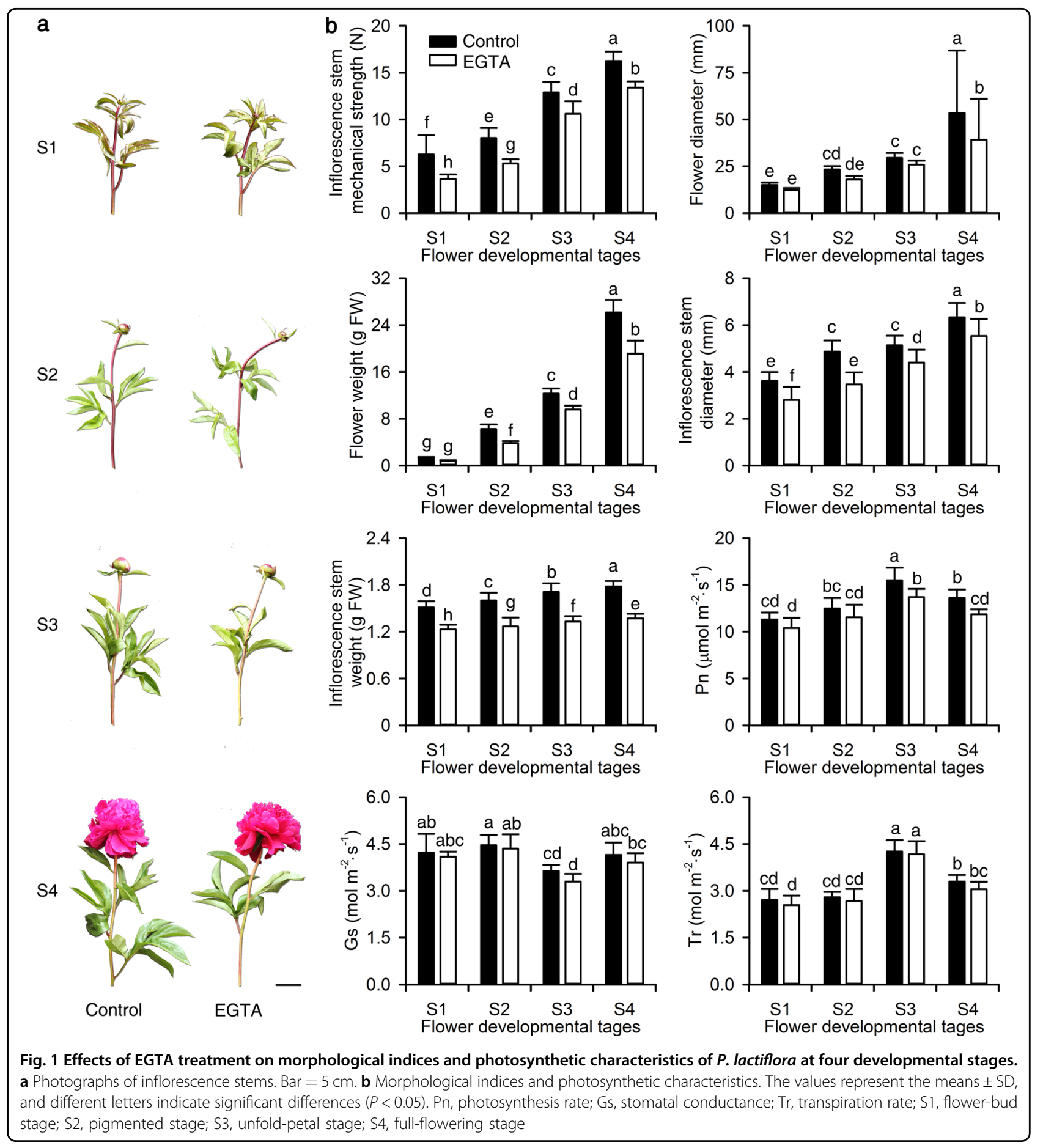

microscopy. The xylem cell walls at S1 and S2 did not stain red, whereas the secondary wall in the xylem, which contains high levels of lignin, stained red at S3 and S4 (Fig. 2b). The staining intensity was evaluated by comparing the brightness of the stain color. There was less secondary wall staining in EGTA-treated inflorescence stems at S3 and S4 compared to the control, but the difference was not significant. There was significantly less stained area in EGTA-treated inflorescence stems at S3 and S4 compared to the control stems.

\section{Microstructure observations}

We examined the inflorescence stem transverse sections by scanning electron microscopy (SEM). The walls in the xylem cells thickened from S2 to S4 (Fig. 3a). With EGTA treatment, there were significantly fewer xylem cells with 

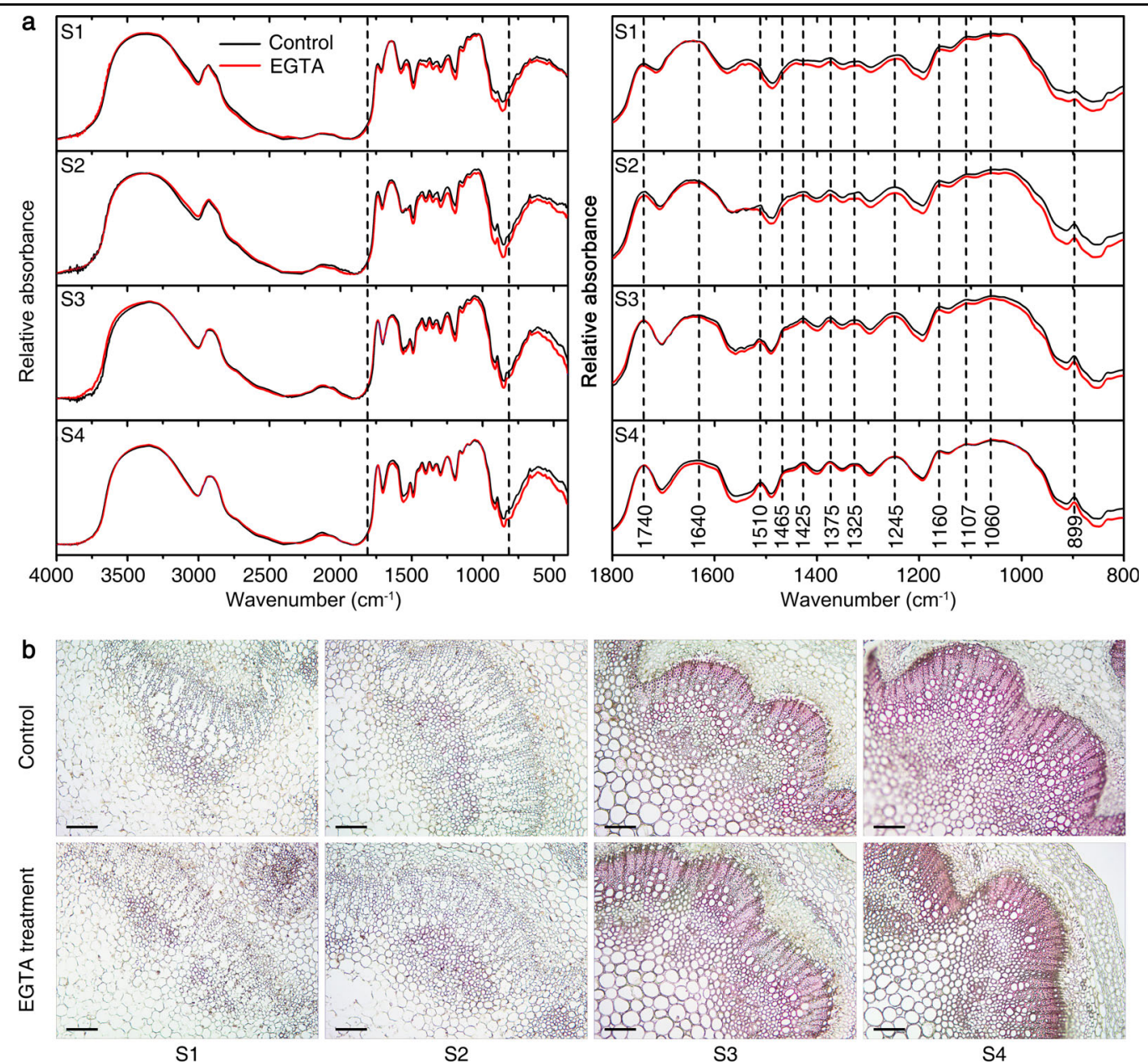

Fig. 2 Effects of EGTA treatment on cell wall compositions of $P$. lactiflora inflorescence stems. a Absorption FTIR spectra of the cell wall in the 4000-400 $\mathrm{cm}^{-1}$ and 1800-800 $\mathrm{cm}^{-1}$ regions. b Transverse sections of $8 \mu \mathrm{m}$ thickness were stained with phloroglucinol-HCl, which selectively stains

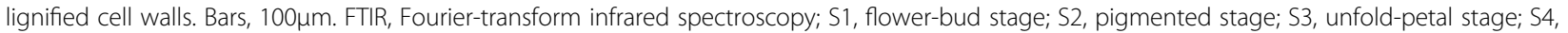
full-flowering stage

thickened secondary walls at S4 compared to that in the same area of the untreated control. To verify the difference in the number of xylem cell layers with thickened secondary walls in inflorescence stems after EGTA treatment, transverse sections were observed under an optical microscope, which revealed the same result (Fig. 3b). The alteration of the thickened secondary walls in xylem cells was further analyzed by transmission electron microscopy (TEM). TEM verified the secondary wall formation in the xylem cells during flowerdevelopment stages (Fig. 3c). EGTA treatment caused fewer thickened secondary walls in the xylem cells at S4 compared to the control, but this difference was not significant.

\section{Differentially expressed proteins detected by iTRAQ}

To investigate the underlying molecular mechanisms in response to EGTA treatment, control and EGTA-treated inflorescence stems at S4 were sampled for proteomic analysis using isobaric tags for relative and absolute quantitation (iTRAQ). As a result, 256,853 spectra with 19,326 matching known peptides were obtained, and 5045 proteins were identified. Under EGTA treatment, 1065 differentially expressed proteins (DEPs) compared to the control were found. Of these, 533 were upregulated and 532 were downregulated. To further explore the functions of these DEPs, gene ontology (GO) and Kyoto encyclopedia of genes and genomes (KEGG) enrichment analyses were implemented.

Of the 1065 DEPs, 554 were annotated via GO analysis. A total of 1186 GO terms were searched, of which 746 were involved in biological processes, 143 in cellular components, and 297 in molecular function categories (Supplementary Table S2A). Twenty keywords encompassed the most important processes that responded to EGTA (Ca, stress, stimulus, signal transduction, 
a

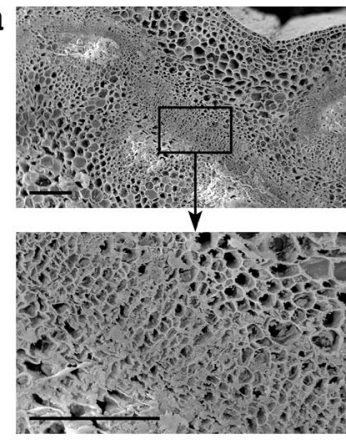

Control (S1)

b

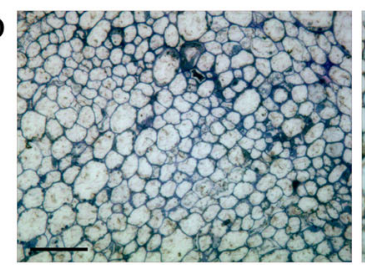

Control (S1)

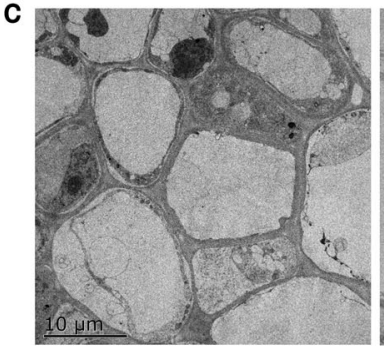

Control (S1)

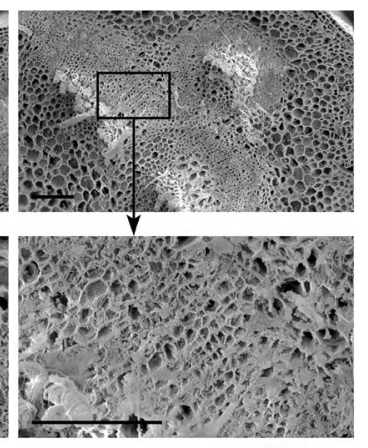

EGTA treatment (S1)

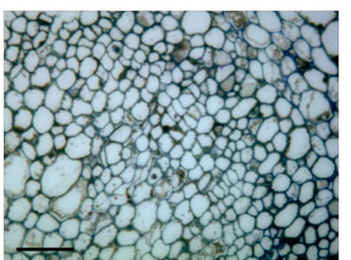

EGTA treatment (S1)

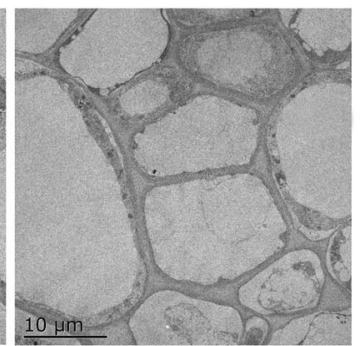

EGTA treatment (S1)

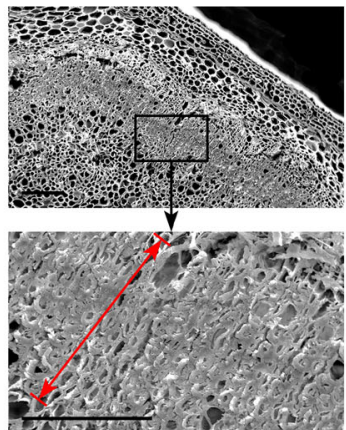

Control (S4)

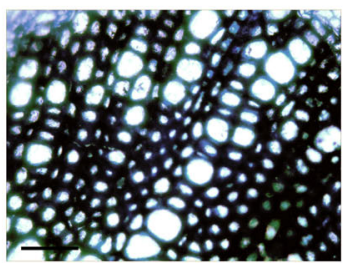

Control (S4)

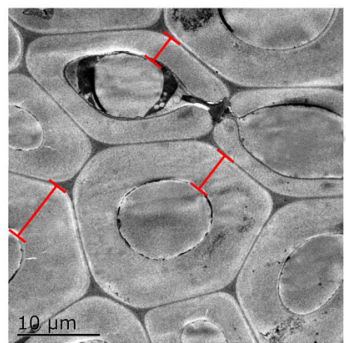

Control (S4)

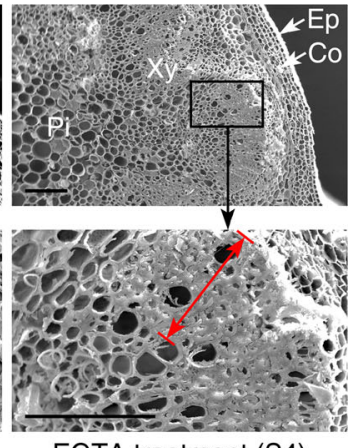

EGTA treatment (S4)

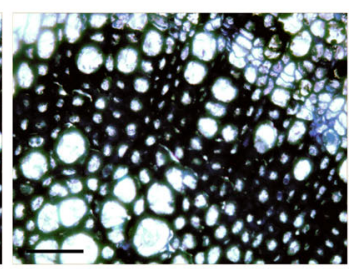

EGTA treatment (S4)

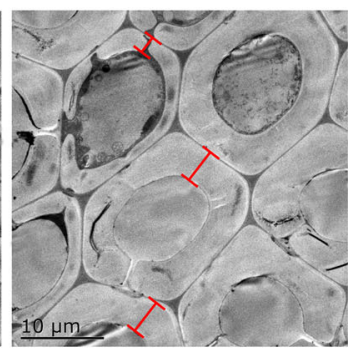

EGTA treatment (S4)

Fig. 3 Effects of EGTA treatment on the microstructures of $\boldsymbol{P}$. lactiflora inflorescence stems at S1 and S4. a Scanning electron microscopy. Micrographs of partial enlargement of the regions are marked by the arrow. Bars, 100 $\mathrm{mm}$. b Optical microscope. Bars, 50 $\mathrm{mm}$. c Transmission electron microscopy. Bars, 10 um. Ep, epidermis; Co, cortex; Xy, xylem; Pi, pith; S1, flower bud stage; S4, full flowering stage

polymerization, transport, assembly, peroxisome, and cytoskeleton) and organelles and components related to inflorescence stem mechanical strength (endoplasmic reticulum, golgi, plasma membrane, cell wall, amino acid, sucrose, glucose, sugar, lignin, cellulose, and hemicellulose). A total of 192 GO terms and 314 DEPs were screened (Fig. 4a and Supplementary Tables S2B and $\mathrm{S} 2 \mathrm{C})$. Most GO terms were related to transport, stimulus, assembly, and cell wall, and these DEPs covered various functions. For example, cinnamyl-alcohol dehydrogenase (CAD) is involved in lignin biosynthesis, calcium-binding protein $(\mathrm{CML})$ is a major $\mathrm{Ca}^{2+}$ sensor involved in $\mathrm{Ca}^{2+}$ signature transduction, and ATP-binding cassette, subfamily $\mathrm{G}$, member 2 (ABCG2) plays an important role in transport.

Through KEGG analysis, 837 DEPs were annotated and assigned to 121 KEGG pathways. These DEPs were significantly enriched $(P<0.05)$ in four pathways, including ribosome (63 DEPs), glycosylphosphatidylinositol (GPI)anchor biosynthesis (3 DEPs), phenylalanine metabolism
(12 DEPs), and phenylpropanoid biosynthesis (24 DEPs; Fig. 4b). Among these four KEGG pathways, phenylalanine metabolism and phenylpropanoid biosynthesis were related to inflorescence stem mechanical strength processes. In the remaining 10 KEGG pathways, the top two were plant-pathogen interactions (22 DEPs) and the citrate cycle (TCA cycle; 15 DEPs; Fig. 4b), which were also related to inflorescence stem mechanical strength processes. Apart from these pathways, another 10 KEGG pathways that might be involved in inflorescence stem mechanical strength processes, including starch and sucrose metabolism, were also found. Abundant DEPs were significantly enriched for starch and sucrose metabolism (22 DEPs) and glycolysis/gluconeogenesis (21 DEPs; Fig. 4). As a result, 144 DEPs were enriched in these KEGG pathways after EGTA treatment. Of them, 80 were upregulated and 66 were downregulated (Supplementary Table S3).

In addition, we found 43 DEPs (17 upregulated and 26 downregulated) from the overlapping KEGG and GO 

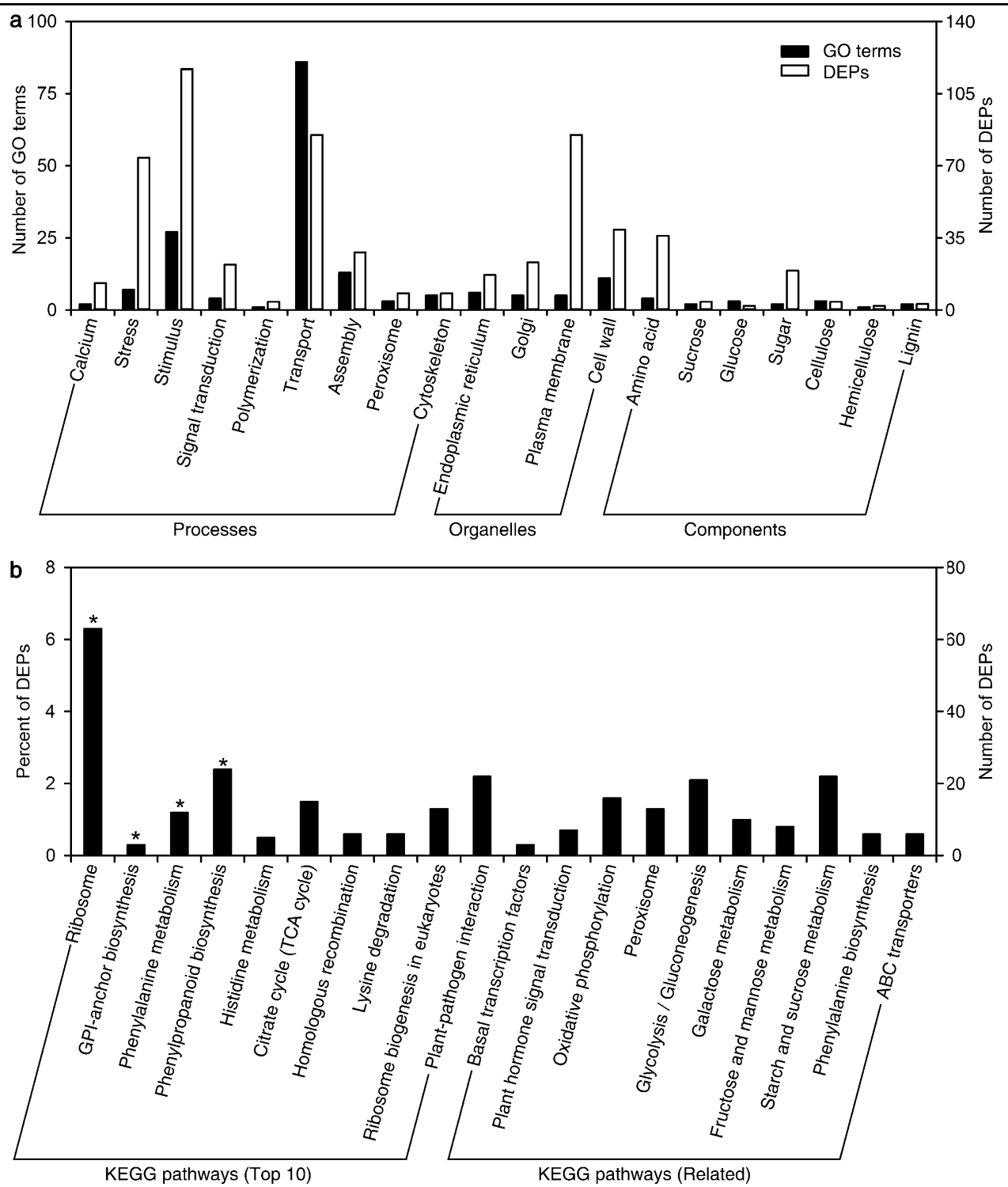

Fig. 4 Effects of EGTA treatment on the proteome of $P$. lactiflora inflorescence stems. a GO enrichment analysis of differentially expressed proteins related to mechanical strength-related processes. b Top $10 \mathrm{KEGG}$ pathways and $10 \mathrm{KEGG}$ enrichment analyses of differentially expressed proteins related to mechanical strength-related processes. * Differentially expressed proteins and significantly enriched pathways. DEPs, differentially expressed proteins; GO, gene ontology; KEGG, Kyoto encyclopedia of genes and genomes

analysis results (Fig. 5 and Supplementary Table S4). These DEPs were related to $\mathrm{Ca}^{2+}$ sensors, signal transduction, oxidative phosphorylation, sugar metabolism, biosynthesis of secondary metabolites, ABC transporters, and peroxisomes. Among the upregulated DEPs, a more than 1.5-fold elevation of the abscisic acid receptor PYR/ PYL family (PYR/PYL), which inhibits the signal transduction of abscisic acid, was observed. The remainder of the upregulated DEPs, such as NADH dehydrogenase Fe$\mathrm{S}$ protein (Ndufs), V/T-type $\mathrm{H}^{+}$-transporting ATPase, and 6-phosphofructokinase 1 (PFK), were involved in oxidative phosphorylation and sugar metabolism. Of the downregulated proteins, DELLA protein, which acts as a negative regulator of gibberellin biosynthesis, was most significantly suppressed by EGTA treatment. CAD, peroxidase (POD), and ATP-binding cassette (ABC) enzymes were involved in lignin biosynthesis, and cellulose synthase A catalytic subunit 7 (CESA7), which is involved in cellulose biosynthesis, was also inhibited by EGTA treatment. Additionally, the $\mathrm{Ca}^{2+}$ sensor CML and MYB transcription factor were also suppressed by EGTA treatment.

\section{Quantitative real-time polymerase chain reaction analysis}

$\mathrm{Ca}^{2+}$-binding proteins related to secondary wall biosynthesis were identified through proteomic analyses. To 


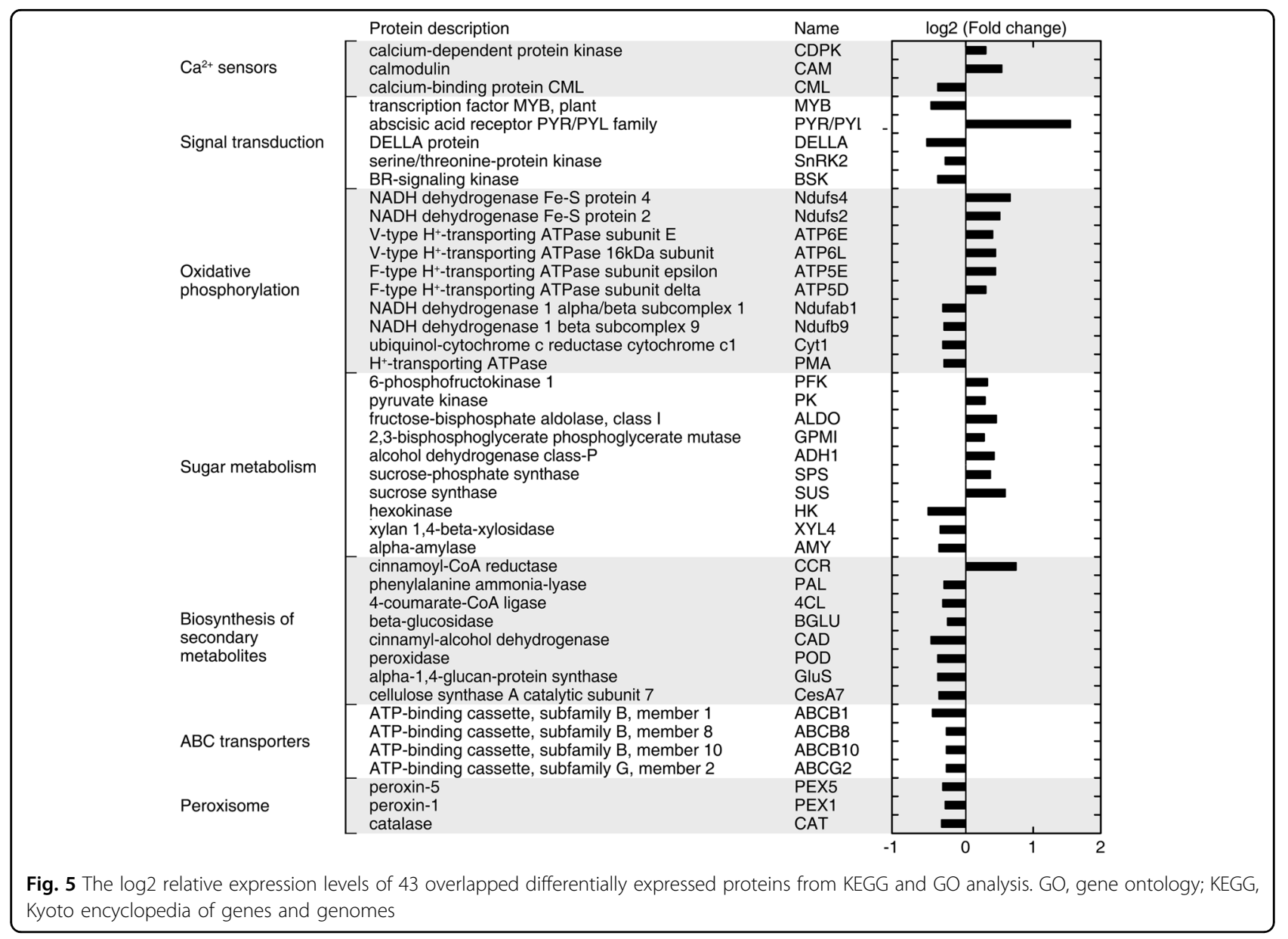

characterize the effect of EGTA treatment on $\mathrm{Ca}^{2+}$ binding and secondary wall biosynthesis in inflorescence stems, we examined the expression of genes corresponding to these proteins by quantitative real-time polymerase chain reaction (qRT-PCR). These genes included calmodulin $(\mathrm{CaM}) /$ $C M L$ and calcium-dependent protein kinase (CDPK), which are involved in $\mathrm{Ca}^{2+}$ binding, and an MYB gene that acts as a transcription factor regulating secondary wall biosynthesis. Additionally, phenylalanine ammonia-lyase gene $(P A L)$, 4-coumarate-CoA ligase (4CL), and $C A D$, which are involved in the phenylpropanoid pathway and important for monolignol synthesis, were analyzed, as well as $P O D$ and $A B C$ genes (such as $A B C C 2$ and $A B C G 2$ ), which are related to monolignol transport. We also analyzed the expression of calcineurin B-like protein-interacting protein kinase (CIPK), cinnamate 4-hydroxylase $(\mathrm{C} 4 \mathrm{H})$, cinnamoyl-CoA reductase $(C C R)$, caffeoyl shikimate esterase (CSE), caffeic acid 3-Omethyltransferase (COMT), and caffeoyl-CoA 3-O-methyltransferase $(C C O A O M T)$, which are related to $\mathrm{Ca}^{2+}$-binding proteins and secondary wall biosynthesis.

$C D P K, C A M$, and $A B C C 2$ were expressed at the highest levels, whereas $P A L, C 4 H, 4 C L$, and $P O D$ were expressed at the lowest levels (Fig. 6a). With EGTA treatment, the expression levels of $C M L, C I P K, N A C, M Y B, P A L, C C R$, $C S E, C O M T$, and $A B C C 2$ were lower by about $79,49,77$, $39,65,48,84,49$, and $69 \%$, respectively, compared to the untreated control. Lower expression levels of WRKY, 4CL, $C C O A O M T$, and $P O D$ were also observed in response to EGTA treatment at the S4 stage of development. The expression levels of the $C 4 H$ and $A B C G 2$ genes were lower by about $88,25 \%$ and $73,28 \%$ compared to the control at S1 and S4, respectively. The expression levels of the $C D P K$ and $C A M$ genes were significantly lower in EGTA-treated inflorescence stems at S3 and S4. In contrast, the expression of these two genes increased in EGTA-treated inflorescence stems at $\mathrm{S} 1$ and $\mathrm{S} 2$. For $C A D$, there was no significant difference in expression between the control and EGTA-treated plants. EGTA stimulated the expression of genes involved in $\mathrm{Ca}^{2+}$ signal transduction and lignin synthesis.

\section{Discussion}

$\mathrm{Ca}^{2+}$ deficiency is very common in nature and can severely affect plant growth, development, and metabolism $^{1}$. However, the molecular mechanisms of $\mathrm{Ca}^{2+}$ deficiency in P. lactiflora are unknown. In this study, we 


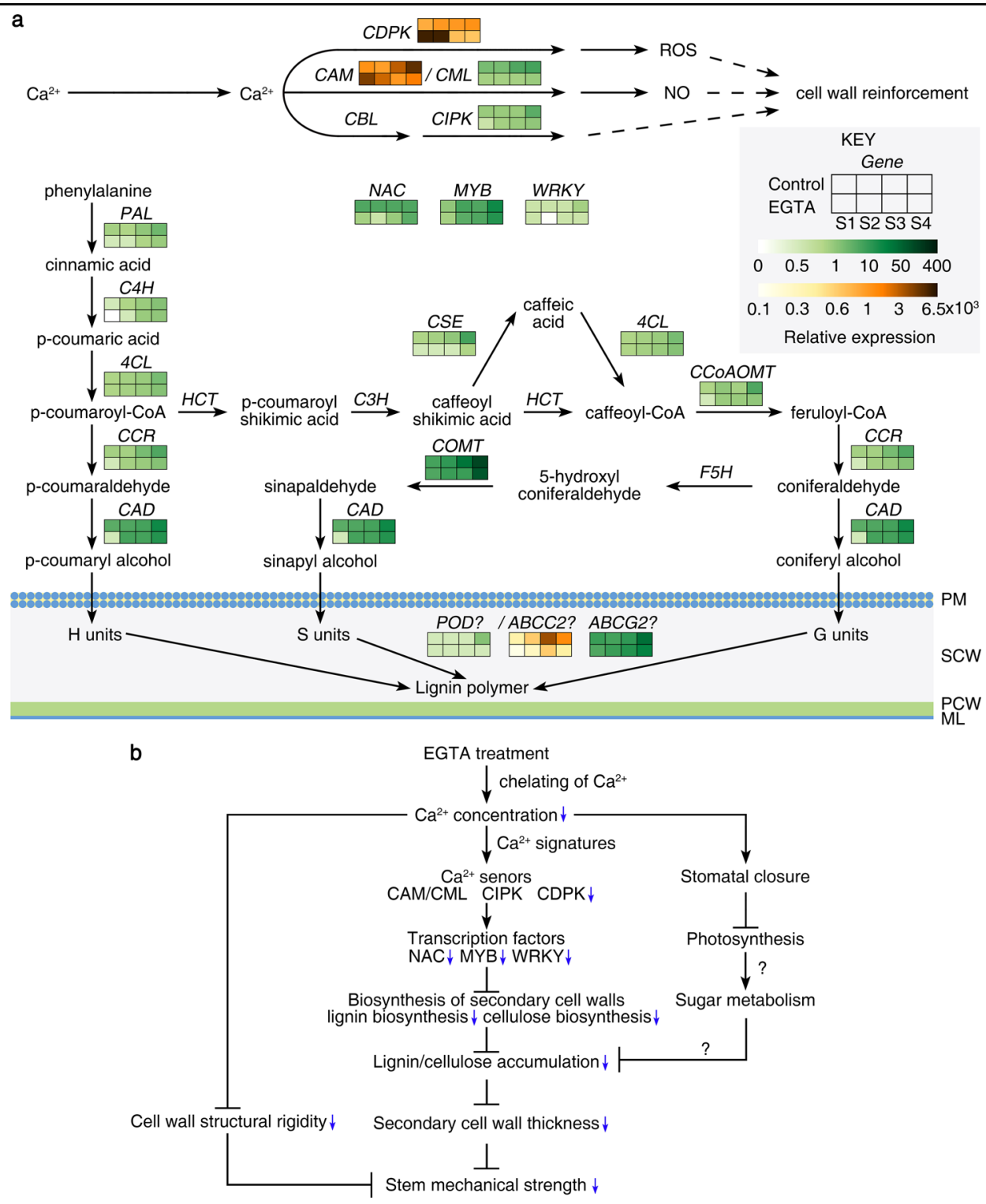

Fig. 6 Effects of EGTA treatment on key genes related to mechanical strength and a proposed pathway for EGTA-mediated reduction of mechanical strength of $\boldsymbol{P}$. lactiflora inflorescence stems. a Heat maps of the expression of 23 genes involved in Ca signal transduction and secondary cell wall biosynthesis at four developmental stages. PM, plasma membrane; SCW, secondary cell wall; PCW, primary cell wall; ML, middle lamella. b Proposed pathway for EGTA-mediated weakness of the mechanical strength of Paeonia lactiflora inflorescence stems. ML, middle lamella; PCW, primary cell wall; PM, plasma membrane; SCW, secondary cell wall; S1, flower-bud stage; S2, pigmented stage; S3, unfold-petal stage; S4, fullflowering stage

found that $\mathrm{Ca}^{2+}$ deficiency in P. lactiflora significantly inhibited growth and development, especially for the upper inflorescence stems. EGTA reduced $\mathrm{Ca}^{2+}$ in the cell wall, lignin deposition, and the number of xylem cell layers with thickened secondary walls. Also, we used iTRAQ to analyze the DEPs in EGTA-treated inflorescence stems at $\mathrm{S} 4 . \mathrm{Ca}^{2+}$ deprivation induced a signal-like stress, which was decoded by $\mathrm{Ca}^{2+}$ sensors, inducing downstream physiological responses. Simultaneously, sugar and energy metabolism and secondary metabolites were affected by the lack of $\mathrm{Ca}^{2+}$. Furthermore, qRT-PCR analyses verified that $\mathrm{Ca}^{2+}$ deprivation reduced the biosynthesis and accumulation of the secondary metabolites used to form lignin.

In ornamental plants, morphological characteristics, especially inflorescence stem mechanical strength, play crucial roles in the quality of cut flowers. Inflorescence stem mechanical strength is correlated with internode number, stem length, weight, and diameter ${ }^{21,23}$. In $P$. lactiflora, there is a positive correlation between 
inflorescence stem mechanical strength and stem weight and diameter ${ }^{12}$. In our study, EGTA treatment led to a comprehensive inhibition of $P$. lactiflora plant development, reducing the weight, diameter, and mechanical strength of inflorescence stems. Mechanical support of plants is mainly contributed by secondary walls ${ }^{13,16}$, and stem mechanical strength is related to the thickness of the secondary walls. For example, Aohara ${ }^{24}$ et al. reported that the thickness of secondary walls of $O$. sativa under the epidermal layer in rice brittle culm 5 (brittle node) mutants is notably thinner than those in wild-type nodes, and similar results were found in the flexible culm 1 mutants ${ }^{16}$. In our study, similar results were found for secondary walls, which were thinner with EGTA treatment compared to the control. The thinner thickened secondary walls distributed around the xylem are important for stem mechanical strength in P. lactiflora, but the thickened secondary walls of cells under the epidermal layer are not. Interestingly, we found a nearly $50 \%$ decrease in the number of xylem cells in thickened secondary walls after EGTA treatment compared to controls. The reduction in xylem cells in thickened secondary walls (reduction of area with thickened secondary walls) was more important than the reduction of these thickened secondary walls in causing loss of mechanical strength.

Secondary walls are composed mainly of the polysaccharides cellulose and hemicellulose, as well as lignin and cell wall proteins. Mechanically, secondary walls can be compared to reinforced concrete, with the cellulose microfibrils that are embedded in an amorphous matrix of lignin 25 being analogous to steel rods . Therefore, stem mechanical strength is determined mainly by the properties of the secondary walls, especially lignin ${ }^{26}$. Wang et al. ${ }^{21}$ reported that among the three genotypes of wheat (Triticum aestivum L.), the genotype with the lowest bending stress contained the least lignin. In O. sativa, decreased accumulation of lignin was also observed in brittle culm 5 nodes $^{24}$. In ornamental plants, similar results have been reported for G. jamesonii ${ }^{14}$ and P. lactiflora ${ }^{8}$. In our study, we also found less lignin accumulation in EGTA-treated plants compared to controls. The weakened inflorescence stems were primarily due to the decreased lignin accumulation induced by EGTA treatment.

The transcriptional regulation of secondary wall deposition is a multi-leveled, hierarchical network, mainly regulated by $N A C$ and $M Y B$ transcription factors. These regulators together activate downstream transcription factors and secondary wall biosynthetic genes ${ }^{27}$. In this study, both the $N A C$ and $M Y B$ transcription factors had lower expression in response to EGTA treatment compared to the control. NAC transcription factors are the master switches that activate secondary wall biosynthesis in vessels and fibers ${ }^{28}$. The MYB46 and MYB83 transcription factors are second-level master switches that activate the expression of many lignin biosynthetic genes $^{29}$. The suppression of $N A C$ and $M Y B$ transcription factors by EGTA treatment affected the expression of downstream transcription factors and secondary wall biosynthetic genes and eventually influenced secondary wall deposition. However, the functions of $N A C$ and $M Y B$ in this study were not conclusive, and additional studies are needed.

Lignin is a phenolic component of cell walls that plays a role in maintaining cell wall rigidity and can be categorized as hydroxyphenyl $(H)$, guaiacyl $(G)$, or syringyl $(S)$ $\operatorname{lignin}^{30,31}$. The lignin monomer-biosynthesis pathway is well established, and several genes for lignin biosynthesis have been identified, including $P A L, C 4 H, 4 C L, C C R$, $C A D, \quad p$-hydroxycinnamoyl-CoA:quinate/shikimate $p$ hydroxycinnamoyltransferase $(H C T), p$-coumarate 3hydroxylase $(C 3 H), C S E$, ferulate 5-hydroxylase $(F 5 H)$, COMT, and CCoAOMT (Fig. 6a) ${ }^{25,32}$. In our study, the expression of PAL, C4H, 4CL, CCR, CAD, CSE, COMT, and $C C O A O M T$, which are involved in lignin biosynthesis, was examined by qRT-PCR. They all had lower expression levels in EGTA-treated inflorescence stems, especially $P A L, C S E$, and COMT, compared to the control. Twentyfour DEPs were significantly enriched in phenylpropanoid biosynthesis, and PAL, 4CL, and CAD were all expressed at lower levels in EGTA-treated inflorescence stems compared to the control. These genes are related to lignin accumulation. Lignin in stem cell walls of $P A L$-knockdown plants in Brachypodium distachyon is reduced by approximately $43 \%^{33}$. Downregulation of $\mathrm{C} 4 \mathrm{H}$ in hybrid eucalyptus (Eucalyptus urophylla $\times$ Eucalyptus grandis) ${ }^{34}$, $4 C L$ in hybrid poplar (Populus tremula $\times$ Populus alba) ${ }^{35}$, $C C R$ in birch (Betula platyphylla $\times$ Betula pendula) ${ }^{36}$, $C A D$ in Arabidopsis thaliana ${ }^{37}$, and a CCoAOMT homolog in tobacco (Nicotiana tabacum) ${ }^{38}$ leads to varying degrees of reduction in lignin content compared to controls. The suppression of these genes also affects plant development, especially the repression of $C C R$, which reduces the thickness of secondary walls. The expression level of COMT is lower in Chlorogalum grandiflorum varieties with a poor vase life, which is consistent with reduced lignin content and pedicel rigidity $^{39}$. The CSE-2 loss-of-function mutant shows the typical phenotype of lignin-deficient mutants ${ }^{40}$. Low expression of lignin biosynthesis-related genes in EGTAtreated inflorescence stems caused a reduction in lignin accumulation.

EGTA chelates cell wall-associated $\mathrm{Ca}^{2+}$, and it does not cross the cell membrane ${ }^{41}$. In our study, the concentration of $\mathrm{Ca}$ in inflorescence stem cell walls was lower in plants treated with EGTA, indicating that EGTA chelated $\mathrm{Ca}^{2+}$ in the cell wall. $\mathrm{Ca}^{2+}$ binds with pectin and plays an important role in cell wall structural rigidity. 
Chelation of cell wall-associated $\mathrm{Ca}^{2+}$ reduced the $\mathrm{Ca}^{2+}$ concentration in cell walls and caused a low $\mathrm{Ca}^{2+}$ environment in the cytoplasm. We surmised that like stimuli such as mechanical injury, cold or ABA, which induce spontaneous $\mathrm{Ca}^{2+}$ oscillations, EGTA treatment may also induce $\mathrm{Ca}^{2+}$ oscillations and generate a $\mathrm{Ca}^{2+}$ signature. Plants have a unique repertoire of $\mathrm{Ca}^{2+}$-binding proteins to decode $\mathrm{Ca}^{2+}$ signatures in the gene families of CAMs/ CMLs, CDPKs, and CIPKs ${ }^{42,43}$. These proteins sense the $\mathrm{Ca}^{2+}$ signature and activate downstream transcription factor activity and gene expression to alter biochemical function through reversible phosphorylation ${ }^{7}$. We found that the expression levels of proteins involved in oxidative phosphorylation changed in response to EGTA treatment. The expression of $\mathrm{H}^{+}$-transporting ATPases and several NADH dehydrogenase enzymes was upregulated, whereas the expression of $\mathrm{NADH}$ dehydrogenase Fe-S proteins and V/F-type $\mathrm{H}^{+}$-transporting ATPases was downregulated, which suggested that EGTA application affected the phosphorylation of proteins involved in the TCA cycle and glycolysis in inflorescence stems and was also related to signal transduction. $C D P K, \mathrm{a} \mathrm{Ca}^{2+}$ sensor, plays an important role in plant cell wall development and secondary growth. For example, Zhao et al. ${ }^{44}$ found a major role for $C D P K 11 / 24$ function in plant pollen-tube growth in double mutant lines, and Matschi et al. ${ }^{45}$ reported that secondary growth is inhibited by a single CDPK (AtCPK28) loss-of-function mutant in Arabidopsis. CAM and CML, members of the NAC, MYB, and WRKY TF families, regulate secondary wall biosynthesis and interact with $\mathrm{Ca}^{2+} / \mathrm{CaM}^{25,46}$. In our study, the expression levels of these $\mathrm{Ca}^{2+}$ signal sensors were different in treated plants compared to controls, suggesting that EGTA application generated $\mathrm{Ca}^{2+}$ signatures that were sensed by CDPK, CAM/CML, and CIPK. The differences in the expression levels of these proteins influenced downstream secondary wall development and thereby reduced the inflorescence stem mechanical strength in $P$. lactiflora.

$\mathrm{Ca}^{2+}$ deprivation inhibits photosynthesis by reducing water absorbance and regulation, resulting in leaf wilting and closure of the stomata on the leaves. This prevents gas exchange and leads to a reduction in the cellular carbon dioxide $\left(\mathrm{CO}_{2}\right)$ concentration and concomitantly rubisco carboxylase activity ${ }^{19}$. $\mathrm{Pn}, \mathrm{Tr}$, and Gs decreased in Japanese morning glory (Pharbitis nil Chois., cv. Violet) after EGTA treatment ${ }^{47}$, which is consistent with the results of our study. Therefore, $\mathrm{Ca}^{2+}$ plays an important role in photosynthesis, and $\mathrm{Ca}^{2+}$ deprivation would suppress photosynthesis in leaves. The reduction in photosynthesis would cause the yield of photosynthetic products available for secondary wall biosynthesis to also be lower. In this study, the expression levels of proteins functioning in sugar metabolism were upregulated, whereas those of proteins that function in decomposition were downregulated. This result suggested that the reduced dry-matter accumulation was due to the lower rates of photosynthesis and altered sugar metabolism, which affected the synthesis of secondary walls.

\section{Conclusion}

The application of EGTA, a $\mathrm{Ca}^{2+}$ chelator, caused $\mathrm{Ca}^{2+}$ deprivation in P. lactiflora and inhibited plant development, including the mechanical strength of inflorescence stems. We have put forward a hypothetical mechanism by which EGTA application reduced the mechanical strength of inflorescence stems (Fig. 6b). $\mathrm{Ca}^{2+}$ plays an important role in determining the structural rigidity of the cell wall. The application of EGTA chelated $\mathrm{Ca}^{2+}$ in the cell wall and made it more pliable. The low $\mathrm{Ca}^{2+}$ in response to EGTA application induced spontaneous $\mathrm{Ca}^{2+}$ oscillation and generated $\mathrm{Ca}^{2+}$ signatures. The $\mathrm{Ca}^{2+}$ signatures were sensed by $\mathrm{Ca}^{2+}$-binding proteins, which were activated through protein phosphorylation. Via the activities of the NAC, MYB and WRKY TF families, the expression of genes involved in lignin and cellulose biosynthesis was reduced. Lignin and cellulose are both main components of secondary walls, and the reduction of these components affected the development and thickness of the secondary walls. In turn, this decreased the mechanical support of the inflorescence stems. Furthermore, the $\mathrm{Ca}^{2+}$ signatures also induced the closure of the stomata and reduced the rates of photosynthesis. The reduction in photosynthetic products affected sugar metabolism and resulted in a decrease in metabolites available for the formation of secondary walls.

\section{Materials and methods \\ Plant materials and treatment}

P. lactiflora cv. 'Hongyan Zhenghui', grown in the field of the germplasm repository of Yangzhou University, Jiangsu Province, China $\left(32^{\circ} 23^{\prime} \mathrm{N}, 119^{\circ} 24^{\prime} \mathrm{E}\right)$, was used as the experimental material. Specimens were planted in 60 rows with two plants per row in the field and divided into two groups with 30 rows per group. One group was sprayed with $10 \mathrm{mmolL}^{-1}$ EGTA, and the other was sprayed with distilled water as a control. Treatments were done once a week from the leaf-expansion stage on 30 March to the bloom stage, with a total of five applications. During the development of $P$. lactiflora, morphological indices and photosynthetic characteristics were measured every 8 days from 7 April to 1 May, including four developmental stages (S1 to S4), and the upper parts (12 $\mathrm{cm}$ ) of thirty inflorescence stems were collected as samples. Subsequently, 5- to 8-cm lengths of the upper part of inflorescence stems were cut into 5-mm sections and fixed 
with $2.5 \%$ glutaraldehyde (GA) solution in $0.1 \mathrm{molL}^{-1}$ potassium phosphate buffer solution (PBS; $\mathrm{pH}$ 7.8). Other samples were fixed with formalin-aceto-alcohol solution for microstructure observation. The remainder of the inflorescence stem samples was immediately frozen in liquid nitrogen and stored at $-80^{\circ} \mathrm{C}$ until examination.

\section{Morphological indices and photosynthetic characteristics}

Morphological indices were measured as described previously ${ }^{12}$. Fully expanded leaves at the fourth apical node were selected to measure photosynthetic characteristics, including $\mathrm{Pn}, \mathrm{Tr}$, and Gs, using a portable photosynthesis system (LI-6400; Li-Cor, USA) between 8:00 and 10:00 am, before each collection.

\section{Cell wall-composition analysis}

Cell wall materials were extracted from inflorescence stems as described previously ${ }^{48}$. $X$-ray photoelectron spectroscopy determination of cell wall elements was performed on a spectrometer (ESCALAB250Xi; Thermofisher Scientific, USA) using a set monochromatic radiation $\mathrm{A} 1 \mathrm{K \alpha}$ source with a background pressure of $5 \times 10^{-10} \mathrm{mbar}$. Each analysis consisted of a wide survey scan (pass energy $100 \mathrm{eV}$, $1.0 \mathrm{eV}$ step size) FTIR determination of cell wall materials and was analyzed by an infrared spectroscopy (IR) spectrometer (670-IR + 610-IR; Varian, USA) using the $\mathrm{KBr}$ pellet technique. Spectra were taken in the wave number range from 4000 to $400 \mathrm{~cm}^{-1}$ with a resolution of $4 \mathrm{~cm}^{-1}$ and 32 scans per sample. All spectra were normalized and baseline-corrected with OPUS management software.

\section{Histological staining}

Stem sections were fixed with formalin-aceto-alcohol for $2 \mathrm{~h}$ at room temperature and at $4{ }^{\circ} \mathrm{C}$ for a minimum of 1 day. Afterwards, the samples were dehydrated in a graded ethanol series, dehydrated with a xylene-ethanol mixture solution $(1: 3,1: 1,3: 1 ; \mathrm{v} / \mathrm{v})$, and finally dehydrated with a xylene-chloroform mixture $(9: 1 ; \mathrm{v} / \mathrm{v})$ twice. After infiltration and embedding in paraffin, $8 \mu \mathrm{m}$ sections were cut using a rotary microtome (RM2245; Leica, USA) and mounted on glass slides. After the paraffin was removed with xylene, sections were rehydrated in a graded ethanol series followed by distilled water and finally air dried. To detect lignin, the sections were stained with $2 \%(\mathrm{w} / \mathrm{v})$ phloroglucinol (Sigma, China) for 2 min and then treated with $18 \%$ hydrochloric acid. The stained sections were observed immediately under a light microscope (CX31RTSF; Olympus, Japan). For cellulose, the sections were stained with $0.1 \%$ calcofluor white M2R in $0.05 \%$ Evans blue (18909; Sigma, China) for 2 min and observed under a fluorescence microscope with a UV excitation filter SZX2-FUV, a GFP high-performance filter SZX2FGFPHQ, and an RFP filter SZX2-RFP1 for calcofluor staining (CX31RTSF; Olympus, Japan).

\section{Microstructure observation}

Inflorescence stem sections were fixed with $2.5 \% \mathrm{GA}$ in $0.1 \mathrm{molL}^{-1} \mathrm{PBS}$ (pH 7.8) for $2 \mathrm{~h}$ at room temperature and at $4{ }^{\circ} \mathrm{C}$ for more than 1 day. They were rinsed with the same buffer three times (15 min each). For SEM observation, the samples were dehydrated and critical-point dried, sputter-coated with gold, and observed with an SEM (XL-30 ESEM; Philips, Holland) under $5 \mathrm{kV}$. For TEM observation, the samples were post-fixed in $1 \%$ osmium tetroxide in $0.1 \mathrm{molL}^{-1} \mathrm{PBS}(\mathrm{pH} 7.8)$ for $4 \mathrm{~h}$ at $4^{\circ}$ $\mathrm{C}$ after GA. After dehydration in an ethanol series, the samples were infiltrated and embedded in butyl-methyl methacrylate. Seventy-nanometer sections were cut, stained with uranyl acetate and lead citrate, and viewed with a TEM (CM100; Philips, Holland).

\section{Proteome with iTRAQ analysis}

Samples at S4 were used to perform proteome analyses. Protein extraction, quantification, iTRAQ labeling and strong cation-exchange fractionation, LC-ESI-MS/MS analysis, database search, quantification bioinformatics, and annotations were performed as described previously ${ }^{49}$, with a few modifications. Briefly, the extraction and purification of protein followed the manufacturer's instructions. The control samples were labeled with iTRAQ tags $114,115 \mathrm{~N}$, and $115 \mathrm{C}$, and the EGTA-treated samples were labeled with $117 \mathrm{C}, 118 \mathrm{~N}$, and $118 \mathrm{C}$. The combined peptide mixtures were lyophilized. After trypsin digestion, the peptides were desalted on a C18 column (Phenomenex) and dried in a spin vacuum. The desalted peptides $(100 \mu \mathrm{g})$ were labeled with iTRAQ 6-plex reagent in $200 \mathrm{mmolL}^{-1}$ triethylamonium bicarbonat (TEAB) according to the manufacturer's instructions. The peptides labeled with different reagents were combined, vacuum-dried, and separated on an LC-20AB HPLC Pump system (Shimadzu, Japan) coupled with a high-pH RP column. Subsequently, the peptides were injected into the tandem mass spectrometer Q EXACTIVE (Thermofisher Scientific, USA) for data-dependent acquisition detection by nano-electrospray ionization.

Raw data were processed with OpenMS software and searched against the SwissProt and common MS contaminant database using Mascot software. Trypsin was chosen as the enzyme with one missed cleavage allowed. The fixed modification carbamidomethylation was set for cysteine and the variable modification oxidation for methionine. The peptide tolerance was set as $0.05 \mathrm{Da}$, and the MS/MS tolerance was set as $0.1 \mathrm{Da}$. The ratio of each protein is given by the geometric mean of the protein ratios measured from all replicates. Student's $t$ test was used to analyze the significance of protein geometric ratios, and the Benjamini-Hochberg multiple hypothesis test correction was employed to correct the $P$ values. DEPs were screened out using 1.2 normalized protein 
geometric ratios at a $P<0.05$ level with $5 \%$ false discovery rate (FDR) correction.

\section{qRT-PCR analyses}

Gene transcript levels were analyzed using qRT-PCR with a BIO-RAD CFX ConnectTM Optics Module (BioRad, USA). cDNA was synthesized from RNA using the PrimeScript $^{\circledast}$ RT Reagent Kit With gDNA Eraser (TaKaRa, Japan). All gene-specific primers in this study are shown in Supplementary Table S5. qRT-PCR was performed using SYBR ${ }^{\circledast}$ Premix Ex TaqTM (Perfect Real Time) (TaKaRa, Japan). The amplification was carried out under the following conditions: $55^{\circ} \mathrm{C}$ for 2 min, followed by an initial denaturation step at $95^{\circ} \mathrm{C}$ for $30 \mathrm{~s}$, and 40 cycles at $95^{\circ} \mathrm{C}$ for $5 \mathrm{~s}, 55^{\circ} \mathrm{C}$ for $15 \mathrm{~s}$, and $72^{\circ} \mathrm{C}$ for $30 \mathrm{~s}$. Relative expression levels of target genes were calculated by the $2^{-\triangle \Delta \mathrm{Ct}}$ comparative threshold cycle method $^{50}$.

\section{Statistical analysis}

All experiments described here were repeated three times in a completely randomized design. Primers were designed using the Primer 5.0 program. All data were means of three replicates with standard deviations. The results were analyzed for variance using the SAS/STAT statistical analysis package (version 6.12; SAS Institute, Cary, NC, USA).

\section{Acknowledgements}

This work was supported by the Natural Science Foundation of China (31572148), the Natural Science Fund for Excellent Young Scholars of Yangzhou City (YZ2017097), the Building Project of Combined and Major Innovation Carrier of Jiangsu Province (BM2016008), the Program of Key Members of Yangzhou University Outstanding Young Teacher, and the Priority Academic Program Development from Jiangsu Government.

\section{Authors' contributions}

J.T. planned and designed the experiments. Y.T., D.Z., and J.M. performed the experiments. D.Z. and Y.T. conducted fieldwork, analyzed the data, and wrote the manuscript. All authors have carefully read and approved the final manuscript.

\section{Conflict of interest}

The authors declare that they have no conflict of interest.

Supplementary Information accompanies this paper at (https://doi.org/ 10.1038/541438-019-0117-7).

Received: 11 August 2018 Revised: 19 December 2018 Accepted: 30 December 2018

Published online: 01 March 2019

\section{References}

1. Hepler, P. K. Calcium: a central regulator of plant growth and development. Plant Cell 17, 2142-2155 (2005)

2. Kudla, J., Batistič, O. \& Hashimoto, K. Calcium signals: the lead currency of plant information processing. Plant Cell 22, 541-563 (2010).
3. Zhang, C. Y., Shi, W. S., Ma, K. S., Li, H. J. \& Zhang, F. X. EGTA, a calcium chelator, affects cell cycle and increases DNA methylation in root tips of Triticum aestivum L. Acta Soc. Bot. Pol. 85, 3502 (2016).

4. Bakeer, S. M. Effect of ammonium nitrate fertilizer and calcium chloride foliar spray on fruit cracking and sunburn of Manfalouty pomegranate trees. Sci. Hortic. 209, 300-308 (2016).

5. Xu, D. H. et al. Calcium alleviates decreases in photosynthesis under salt stress by enhancing antioxidant metabolism and adjusting solute accumulation in Calligonum mongolicum. Conserv. Physiol. 5, 1-8 (2017).

6. Choi, W. G., Hilleary, R., Swanson, S. J., Kim, S. H. \& Gilroy, S. Rapid, long-distance electrical and calcium signaling in plants. Annu. Rev. Plant Biol. 67, 1-21 (2016).

7. Dodd, A. N., Kudla, J. \& Sanders, D. The language of calcium signaling. Annu. Rev. Plant Biol. 61, 593-620 (2010).

8. Li, C. Z., Tao, J., Zhao, D. Q., You, C. \& Ge, J. T. Effect of calcium sprays on mechanical strength and cell wall fractions of herbaceous peony (Paeonia lactiflora Pall.) inflorescence stems. Int. J. Mol. Sci. 13, 4704-4713 (2012).

9. Perik, R. R. J., Razé, D., Harkema, H., Zhong, Y. \& van Doorn, W. G. Bending in cut Gerbera jamesonii flowers relates to adverse water relations and lack of stem sclerenchyma development, not to expansion of the stem central cavity or stem elongation. Postharvest Biol. Technol. 74, 11-18 (2012).

10. Li, C. Z., Sun, Y., Zhao, D. Q., Feng, L. G. \& Tao., J. Relationship between inflorescence stem mechanical strength and some elements contents of herbaceous peony (Paeonia lactiflora Pall.). Southwest China J. Agric. Sci. 29, 1214-1218 (2016). (in Chinese).

11. Lee, C. H. \& Nam, M. K. Enhancement of stem firmness in standard chrysanthemum 'Baekma' by foliar spray of liquid calcium compounds. Korean. J. Hortic. Sci. 29, 298-305 (2011).

12. Zhao, D. Q. et al. Effects of inflorescence stem structure and cell wall components on the mechanical strength of inflorescence stem in herbaceous peony. Int. J. Mol. Sci. 13, 4993-5009 (2012).

13. Ansari, M. J., Kumar, R., Singh, K. \& Dhaliwal, H. S. Characterization and molecular mapping of EMS-induced brittle culm mutants of diploid wheat (Triticum monococcum L.). Euphytica 186, 165-176 (2012).

14. Perik, R. R. J., Razé, D., Ferrante, A. \& Doorn, W. G. V. Stem bending in cut Gerbera jamesonii flowers: effects of a pulse treatment with sucrose and calcium ions. Postharvest Biol. Technol. 98, 7-13 (2014).

15. Hirano, K. et al. Rice Brittle culm 3 (bc3) encodes a classical dynamin OsDRP2B essential for proper secondary cell wall synthesis. Planta $\mathbf{2 3 2}$, 95-108 (2010).

16. Li, X. J. et al. Flexible culm 1 encoding a cinnamyl-alcohol dehydrogenase controls culm mechanical strength in rice. Plant Mol. Biol. 69, 685-697 (2009).

17. Fang, K. F., Zhang, Q., Yang, R., Cao, Q. Q. \& Qin, L. Cytochalasin b treatment of apple (Malus pumila Mill.) pollen tubes alters the cytoplasmic calcium gradient and causes major changes in the cell wall components. Russ. J. Plant Physiol. 65, 384-393 (2018)

18. Zhi, H. H. et al. Ultrasound enhances calcium absorption of jujube fruit by regulating the cellular calcium distribution and metabolism of cell wall polysaccharides. J. Sci. Food Agric. 97, 5202-5210 (2017).

19. Chao, L. et al. Influences of calcium deficiency and cerium on growth of spinach plants. Biol. Trace Elem. Res 121, 266-275 (2008).

20. Legocka, J. \& Sobieszczuk-Nowicka, E. Calcium variously mediates the effect of cytokinin on chlorophyll and LHCPII accumulation during greening in barley leaves and cucumber cotyledons. Acta Biologica. Cracoviensia. s. Botanica. 56, 27-34 (2014).

21. Wang, J. et al. Effects of stem structure and cell wall components on bending strength in wheat. Chin. Sci. Bull. 51, 815-823 (2006).

22. Zhong, R. Q. et al. Essential role of caffeoyl coenzyme a O-methyltransferase in lignin biosynthesis in woody poplar plants. Plant Physiol. 124, 563-577 (2000).

23. Sreeja, R. et al. Association of lignin and Flexible culm 1 (fc1) ortholog in imparting culm strength and lodging resistance in kodo millet (Paspalum scrobiculatum L). Mol. Breed. 36, 149 (2016).

24. Aohara, T. et al. Rice Brittle culm 5 (brittle node) is involved in secondary cell wall formation in the sclerenchyma tissue of nodes. Plant Cell Physiol. $\mathbf{5 0}$ 1886-1897 (2009).

25. Kumar, M., Campbell, L. \& Turner, S. Secondary cell walls: biosynthesis and manipulation. J. Exp. Bot. 67, 515-531 (2016)

26. Speck, T. \& Burgert, I. Plant stems: functional design and mechanics. Annu. Rev Mat. Res. 41, 169-193 (2011) 
27. Nakano, Y., Yamaguchiz, M., Endo, H., Rejab, N. A. \& Ohtani, M. NAC-MYB-based transcriptional regulation of secondary cell wall biosynthesis in land plants. Front. Plant Sci. 6, 288 (2015).

28. Zhong, R. Q., Lee, C. H. \& Ye, Z. H. Functional characterization of poplar wood-associated NAC domain transcription factors. Plant Physiol. 152, 1044-1055 (2010).

29. Zhong, R. Q. \& Ye, Z. H. MYB46 and MYB83 bind to the SMRE sites and directly activate a suite of transcription factors and secondary wall biosynthetic genes. Plant Cell Physiol. 53, 368-380 (2012).

30. Boerjan, W., Ralph, J. \& Baucher, M. Lignin biosynthesis. Annu. Rev. Plant Biol. 54, 519-546 (2003)

31. Wang, J. K. \& Chapple, C. The origin and evolution of lignin biosynthesis. New Phytol. 187, 273-285 (2003).

32. Faraji, M. et al. Mathematical models of lignin biosynthesis. Biotechnol. Biofuels 11, 34 (2018).

33. Cass, C. L. Effects of phenylalanine ammonia lyase (PAL) knockdown on cell wall composition, biomass digestibility, and biotic and abiotic stress responses in Brachypodium. J. Exp. Bot. 66, 4317-4345 (2015).

34. Sykes, R. W. et al. Down-regulation of p-coumaroyl quinate/shikimate $3^{\prime}$ hydroxylase $\left(\mathrm{C}^{\prime} \mathrm{H}\right)$ and cinnamate 4-hydroxylase $(\mathrm{C} 4 \mathrm{H})$ genes in the lignin biosynthetic pathway of Eucalyptus urophyllaxE. grandis leads to improved sugar release. Biotechnol. Biofuels 8, 128 (2015).

35. Voelker, S. L. et al. Antisense down-regulation of $4 C L$ expression alters lignification, tree growth, and saccharification potential of field-grown poplar. Plant Physiol. 154, 874-886 (2010).

36. Zhang, W. B. et al. Functional characterization of cinnamoyl-coa reductase (CCR) in birch (Betula platyphyllaxBetula pendula) through overexpression and suppression analysis. Physiol. Plant. 154, 283-296 (2015).

37. Thévenin, J. et al. The simultaneous repression of CCR and CAD, two enzymes of the lignin biosynthetic pathway, results in sterility and dwarfism in Arabidopsis thaliana. Mol. Plant 4, 70-82 (2011).

38. Pang, S. L. et al. Isolation and characterization of CCOAOMT in interspecifc hybrid of Acacia auriculiformis $\times$ Acacia mangium - a key gene in lignin biosynthesis. Genet. Mol. Res 13, 7217-7238 (2014).
39. LV, G. S. et al. The anatomy and physiology of spray cut chrysanthemum pedicels, and expression of a caffeic acid 3-O-methyltransferase homologue. Postharvest Biol. Technol. 60, 244-250 (2011).

40. Vargas, L. et al. Improving total saccharifcation yield of Arabidopsis plants by vessel-specifc complementation of caffeoyl shikimate esterase (cse) mutants. Biotechnol. Biofuels 9, 139 (2016).

41. Wang, B., Zhao, H., Duan, C. \& Sakanishi, A. Effects of cell wall calcium on the growth of Chrysanthemum callus under sound stimulation. Colloids Surf. B. Biointerfaces 25, 189-195 (2002).

42. Kudla, J. et al. Advances and current challenges in calcium signaling. New Phytol. 218, 414-431 (2018).

43. Boonburapong, B. \& Buaboocha, T. Genome-wide identification and analyses of the rice calmodulin and related potential calcium sensor proteins. BMC Plant Biol. 7, 4 (2007).

44. Zhao, L. N. et al. $\mathrm{Ca}^{2+}$-dependent protein kinase11 and 24 modulate the activity of the inward rectifying $\mathrm{K}^{+}$channels in Arabidopsis pollen tubes. Plant Cell 25, 649-661 (2013).

45. Matschi, S. et al. Function of calcium-dependent protein kinase CPK28 of Arabidopsis thaliana in plant stem elongation and vascular development. Plant J. 73, 883-896 (2013).

46. Doblin, M. S., Kurek, I., Jacob-Wilk, D. \& Delmer, D. P. Cellulose biosynthesis in plants: from genes to rosettes. Plant Cell Physiol. 43, 1407-1420 (2002).

47. Glowacka, K., Tretyn, A., Górecki, R. J. \& Lee, S. H. EGTA inhibits floral induction of Pharbitis nil via its influence on gas exchange properties of stomata. Acta Physiol. Plant 28, 477-481 (2006).

48. Zhao, D. Q., Gong, S. J., Hao, Z. J., Meng, J. S. \& Tao, J. Quantitative proteomics analysis of herbaceous peony in response to paclobutrazol inhibition of lateral branching. Int. J. Mol. Sci. 16, 24332-24352 (2015).

49. Li, C. Z. et al. Effects of spraying calcium on the inflorescence stem quality and leaf photosynthesis of herbaceous peony (Paeonia lactiflora Pall.). Chin. J. Ecol. 31, 2817-2822 (2012).

50. Schmittgen, T. D. \& Livak, K. J. Analyzing real-time PCR data by the comparative CT method. Nat. Protoc. 3, 1101-1108 (2008). 